\title{
Evaluation of phenolic profile, antioxidant and anticholinesterase effects of Fuscoporia torulosa
}

\author{
Ebru Deveci', Gülsen Tel-Çayan², Mehmet Emin Duru (iD*,1 \\ ${ }^{1}$ Department of Chemistry, Faculty of Science, Muğla Sitkı Koçman University, Muğla, Turkey \\ ${ }^{2}$ Department of Chemistry and Chemical Processing Technologies, Muğla Vocational School, Muğla Sitk1 \\ Koçman University, Muğla, Turkey
}

\begin{abstract}
In this study, we investigated antioxidant and anticholinesterase activities of the hexane, chloroform, acetone, methanol and water extracts of $F$. torulosa mushroom with total phenolic contents. Also, HPLC-DAD was used to identify phenolic profile of $F$. torulosa. The acetone and methanol extracts of $F$. torulosa with the highest total phenolic contents showed the highest antioxidant activity in all assays except metal chelating assay. Furthermore, antioxidant activities of the acetone and methanol extract were found to be higher than $\alpha$ tocopherol and BHA used as standards in DPPH', ABTS $^{\cdot+}$ and CUPRAC assays. When $F$. torulosa hexane extract $(41.34 \pm 1.50 \%)$ showed moderate AChE inhibitory activity, the acetone $(40.78 \pm 0.30 \%)$ and methanol $(45.39 \pm 0.65 \%)$ extracts of $F$. torulosa indicated moderate BChE inhibitory activity. Major phenolic compounds were identified as trans-2-hydroxy cinnamic acid (10.05 $\mu \mathrm{g} / \mathrm{g})$, gallic acid $(5.01 \mu \mathrm{g} / \mathrm{g})$ and $p$-coumaric acid $(3.04 \mu \mathrm{g} / \mathrm{g})$. These results suggest that $F$. torulosa mushroom could be used as a valuable natural antioxidant source for pharmaceutical industry.
\end{abstract}

\section{ARTICLE HISTORY}

Received: December 12, 2018

Revised: February 25, 2019

Accepted: February 28, 2019

\section{KEYWORDS}

Fuscoporia torulosa, Phenolic profile, HPLC-DAD,

Antioxidant activity, Anticholinesterase activity

\section{INTRODUCTION}

Free radicals are produced from oxygen during aerobic respiration and excessive amount of formation and accumulation causes oxidative stress [1]. The formation of oxidative stress in living organisms, in particular damages the biomolecules such as DNA, proteins and lipids, resulting in many diseases such as hypertension, ischemia, neurodegenerative diseases and rheumatoid arthritis [2]. Antioxidants prevent or reduce the harmful effects of oxidative stress. The use of synthetic antioxidants is an old practice and the safety of these substances is questioned by consumers. At present, interest in alternative natural compounds with high antioxidant effect is increasing [3].

Alzheimer's disease (AD) eliminates neurons in the cortex and limbic structure in the brain, causing learning and memory loss and behavioral disorders in humans. AD is characterized by a reduction of acetylcholine (ACh) due to damage to cholinergic neurons in some specific parts of the brain, such as the hippocampus and cortex (cholinergic hypothesis) [4]. One effective approach in the treatment of $\mathrm{AD}$ is the inhibition of acetylcholinesterase

*CONTACT: Mehmet Emin Duru $\varangle$ eminduru@mu.edu.tr $\equiv$ Department of Chemistry, Faculty of Science, Mugla Sitki Kocman University, 48000 Mugla, Turkey 
(AChE), which is responsible for the hydrolysis of ACh [5,6]. During aging, a gradual decrease in antioxidant defense mechanism and increased oxidative stress cause neuronal injury and death, which is another neurotoxic pathway causing AD [7]. Previous studies have demonstrated that antioxidant therapy is successful in improving cognitive function and behavioral deficits in patients with mild to moderate $\mathrm{AD}$ [8].

It is well known that mushrooms have therapeutic properties since ancient times. Up to know, many bioactive compounds such as lectins, polysaccharides, terpenoids, alkaloids, sterols and phenolics having anticancer, antioxidant, antitumor, antiinflammatory, antifungal, antibacterial, antiviral, anti-immunomodulatory activities have been isolated from mushrooms. When literature studies are examined, it is seen that mushrooms are used especially due to anticancer activity [9-15]. Mushrooms show beneficial effects on cancer, either directly as antioxidants or preventing genetic factors that cause cancer [16].

Recently, studies on the discovery of bioactive compounds from mushrooms have become more important because of their functional and therapeutic properties. Therefore, in this report, we focused to evaluate antioxidant and anticholinesterase activities of the hexane, chloroform, acetone, methanol and water extracts of $F$. torulosa mushroom with total phenolic contents. Also, phenolic profile of $F$. torulosa were determined by HPLC-DAD.

\section{MATERIAL and METHODS}

\subsection{Mushroom Material}

F. torulosa (Pers.) T. Wagner \& M. Fisch. was collected from Muğla, Turkey, in November-December, 2014 and January, 2015. The voucher specimen has been deposited at the herbarium of Natural Products Laboratory of Muğla Sitkı Koçman University with Fungarium No AT-2436.

\subsection{Instruments and Chemicals}

Bioactivity measurements were carried out on a 96-well microplate reader, SpectraMax 340PC384 (Molecular Devices, Silicon Valley, CA). The measurements and calculations of the activity results were evaluated by using Softmax PRO v5.2 software (Molecular Devices, Silicon Valley, CA).

Pyrocatechol, ethylenediaminetetraacetic acid (EDTA), ethanol, methanol, chloroform, acetone, hexane, ferrous chloride, copper (II) chloride and ammonium acetate were obtained from E. Merck (Darmstadt, Germany). Polyoxyethylene sorbitan monopalmitate (Tween-40), 1,1-diphenyl-2-picrylhydrazyl (DPPH), Folin-Ciocalteu's reagent (FCR), 3-(2-pyridyl)-5,6di(2-furyl)-1,2,4-triazine-5',5"-disulfonic acid disodium salt (ferene), $\beta$-carotene, linoleic acid, $2,2^{\prime}$-azino bis (3-ethylbenzothiazoline-6-sulfonic acid) diammonium salt (ABTS), $\alpha$ tocopherol, neocuproine, butylated hydroxyl anisole (BHA), acetylcholinesterase from electric eels (AChE, Type-VI-S, EC 3.1.1.7, $425.84 \mathrm{U} / \mathrm{mg}$, Sigma), acetylthiocholine iodide, butyrylcholinesterase from horse serum (BChE, EC 3.1.1.8, 11.4 U/mg, Sigma), butyrylthiocholine chloride, 5,5'-dithiobis (2-nitrobenzoic) acid (DTNB), galantamine, fumaric acid, gallic acid, protocatechuic acid, $p$-hydroxy benzoic acid, catechin hydrate, 6,7-dihydroxy coumarin, 2,4-dihydroxy benzoic acid, caffeic acid, vanillin, $p$-coumaric acid, ferulic acid, coumarin, trans-2-hydroxy cinnamic acid, ellagic acid, rosmarinic acid, trans-cinnamic acid were obtained from Sigma Chemical Co. (Sigma-Aldrich GmbH, Sternheim, Germany). All other chemicals and solvents were in analytical grade.

\subsection{Extraction}

The aerial parts of $F$. torulosa $(2.8 \mathrm{~kg})$ were extracted separately with different solvents according to their increasing polarity: hexane, chloroform, acetone, methanol at room 
temperature for $24 \mathrm{~h}$ and four times. Solvents were evaporated on a rotary evaporator at $40^{\circ} \mathrm{C}$. The hexane (10.5 g), chloroform (29.8 g), acetone (38.4 g) and methanol (55.6 g) extracts were obtained. The remaining mushroom part was allowed to stand for one day with water at $80^{\circ} \mathrm{C}$. The water extract of (17.6 g) were obtained by lyophilisation using a freeze-drier. All extracts were stored at $+4^{\circ} \mathrm{C}$ until analysis.

\subsection{Determination of Total Phenolic Content}

The phenolic content of extracts was stated as microgram of pyrocatechol equivalents (PEs) [17]. The phenolic contents were calculated according to the following equation that was obtained from standard pyrocatechol graph:

$$
\text { Absorbance }=0.0176[\text { pyrocatechol }(\mu \mathrm{g})]-0.355\left(r^{2}, 0.9992\right)
$$

\subsection{Analysis of Phenolic Profile}

The phenolic compounds analysis was performed by our recent publication [18] with slight modification. The mushroom sample $(3 \mathrm{~g})$ was extracted with acetone: water $(80: 20 \mathrm{v} / \mathrm{v}$; $30 \mathrm{~mL}$ ) at $-18{ }^{\circ} \mathrm{C}$ for $24 \mathrm{~h}$. After ultrasonic bath for $15 \mathrm{~min}$, the mushroom extract was centrifuged at $4000 \mathrm{rpm}$ for $10 \mathrm{~min}$ and filtered through Whatman no. 4 paper. The residue was then re-extracted by two additional $30 \mathrm{~mL}$ of the acetone: water. The combined extracts were evaporated at $40{ }^{\circ} \mathrm{C}$ under reduced pressure to remove acetone. The obtained extract was solved in water: methanol (80:20) and filtered through a $0.20 \mu \mathrm{m}$ disposable LC filter disk for HPLCDAD. Separation was achieved on an Intertsil ODS-3 reverse phase C18 column $(5 \mu \mathrm{m}, 150$ $\mathrm{mm} \times 4.6 \mathrm{~mm}$ i.d) thermostatted at $40{ }^{\circ} \mathrm{C}$. The solvent flow rate was $1.5 \mathrm{~mL} / \mathrm{min}$. The sample volume injection was $20 \mu \mathrm{L}$. The mobile phases used were: (A) $0.5 \%$ acetic acid in water, (B) $0.5 \%$ acetic acid in methanol. The elution gradient was as follows: $0-20 \% \mathrm{~B}(0-0.01 \mathrm{~min})$; $20-60 \%$ B (0.01-2 min); 60-80\% B (2-15 min); $100 \%$ B (15-30 min); 100-10\% B (3-35 $\mathrm{min}) ; 10-0 \% \mathrm{~B}$ (35-40 min). Detection was carried out photodiode array detector (PDA) using $280 \mathrm{~nm}$ as the preferred wavelength. The phenolic compounds were characterized according to their retention times, and UV data were compared with commercial standards. Three parallel analyses were performed. For the quantitative analysis of phenolic compounds, calibration curves were obtained via the injection of known concentrations $(0.0,0.00782,0.01563$, $0.03125,0.0625,0.125,0.25,0.5$ and $1.0 \mathrm{ppm}$ ) of different standards compounds i.e. gallic acid, fumaric acid, protocatechuic acid, catechin hydrate, $p$-hydroxy benzoic acid, 6,7dihydroxy coumarin, caffeic acid, vanilin, 2,4-dihydroxy benzoic acid, $p$-coumaric acid, ferulic acid, coumarin, trans-2-hydroxy cinnamic acid, ellagic acid, rosmarinic acid, trans-cinnamic acid. The results were expressed as $\mu \mathrm{g}$ per $\mathrm{g}$ of dry weight (dw).

\subsection{Determination of Antioxidant Activity}

Total antioxidant activity by $\beta$-carotene-linoleic acid test, DPPH free radical scavenging assay, ABTS cation radical scavenging assay, cupric reducing antioxidant capacity (CUPRAC) assay and metal chelating activity on $\mathrm{Fe}^{2+}$ assays were carried out according to our earlier publication [19]. BHA, $\alpha$-tocopherol and EDTA were used as antioxidant standards for comparison of the activities. The antioxidant activity results are expressed as $50 \%$ inhibition concentration $\left(\mathrm{IC}_{50}\right)$ and inhibition percentage (\%) at $200 \mu \mathrm{g} / \mathrm{mL}$ and $\mathrm{A}_{0.50}$ which corresponds to the concentration producing 0.500 absorbance for CUPRAC assay.

\subsection{Determination of Anticholinesterase Activity}

Acetylcholinesterase and butyrylcholinesterase inhibitory activity were determined the spectrophotometric method developed by Ellman et al. [20]. AChE from electric eel and $\mathrm{BChE}$ from horse serum were used, acetylthiocholine iodide and butyrylthiocholine chloride were employed as substrates of the reaction. DTNB was used for the measurement of the 
cholinesterase activity. Briefly, $150 \mu \mathrm{L}$ of $100 \mathrm{mM}$ sodium phosphate buffer (pH 8.0), $10 \mu \mathrm{L}$ of the sample solution dissolved in ethanol at different concentrations and $20 \mu \mathrm{L} \mathrm{AChE} \mathrm{or} \mathrm{BChE}$ solution in buffer were mixed and incubated for $15 \mathrm{~min}$ at $25^{\circ} \mathrm{C}$, and $10 \mu \mathrm{L}$ of $0.5 \mathrm{mM}$ DTNB was added. The reaction was then initiated by the addition of $0.71 \mathrm{mM}, 10 \mu \mathrm{L}$ of acetylthiocholine iodide or $0.2 \mathrm{mM}, 10 \mu \mathrm{L}$ of butyrylthiocholine chloride. The hydrolysis of these substrates was monitored spectrophotometrically by the formation of yellow 5-thio-2nitrobenzoate anion as the result of the reaction of DTNB with thiocholine, released by the enzymatic hydrolysis of acetylthiocholine iodide or butyrylthiocholine chloride, respectively, at a wavelength of $412 \mathrm{~nm}$ utilizing a 96-well microplate reader. Galantamine was used as reference compounds. The results were given as inhibition percentage (\%) of the enzyme at 100 $\mu \mathrm{g} / \mathrm{mL}$ concentration of the extracts.

\subsection{Statistical Analysis}

All data on antioxidant and anticholinesterase tests were the average of three parallel sample measurements. Data were recorded as mean \pm S.E.M. Significant differences between means were determined by student's test, $p$ values $<0.05$ were regarded as significant.

\section{RESULTS and DISCUSSION}

\subsection{Total Phenolic Content}

The calibration curve of pyrocatechol $\left(0.0176[\right.$ pyrocatechol $\left.(\mu \mathrm{g})]-0.355 ; r^{2}, 0.9992\right)$ was used to determine the total phenolic content. Table 1 presents the total phenolic contents of the hexane, chloroform, acetone, methanol and water extracts of $F$. torulosa.

The methanol extract $(131.35 \pm 0.29 \mu \mathrm{g}$ PEs $/ \mathrm{mg})$ of $F$. torulosa has the highest level of the phenolic compounds among the other extracts. The total phenolic contents of the extracts were decreased in the order of methanol $>$ acetone $>$ water $>$ hexane $>$ chloroform. Total phenolic content of Inonotus obliquus (Fuscoporia obliqua) ethanol extract was found as $55.94 \pm 1.08 \mathrm{mg}$ GAE/g extract by Zhang et al. [21]. The content of total phenols of $80 \%$ ethanol, $80 \%$ methanol and $95 \%$ ethanol extracts of Inonotus obliquus (Fuscoporia obliqua) expressed as $\mu \mathrm{g}$ of gallic acid equivalents extracted from $100 \mathrm{mg}$ extracts were found as 1388.505, 1404.907 and 662.184 respectively [22]. In the report of Seephonkai et al. [23], total phenolic contents of $50 \% \mathrm{EtOH}$, $80 \% \mathrm{EtOH}$, EtOH, EtOAc extracts of $F$. torulosa were studied and found as $43.80 \pm 0.78$, $54.86 \pm 0.21,62.51 \pm 0.65,16.56 \pm 0.29 \mathrm{mg} \mathrm{GA} / 100 \mathrm{mg}$ of extract, respectively. The results obtained are consistent with the literature. Total phenolic contents of hexane, chloroform, acetone, methanol and water extracts of $F$. torulosa were studied for the first time in this research.

Table 1. Total phenolic contents of the extracts of $F$. torulosa $a^{a}$

\begin{tabular}{llc}
\hline & Total phenolic content $(\mu \mathrm{g}$ PEs/mg extract) \\
\hline \multirow{3}{*}{ Extracts } & Hexane & $42.67 \pm 0.36$ \\
& Chloroform & $19.38 \pm 0.18$ \\
& Acetone & $73.54 \pm 0.08$ \\
& Methanol & $131.35 \pm 0.29$ \\
& Water & $55.50 \pm 0.71$ \\
\hline
\end{tabular}

${ }^{a}$ Values expressed are means \pm S.E.M. of three parallel measurements $(p<0.05)$.

\subsection{Phenolic Profile}

Phenolic profile of $F$. torulosa mushroom was determined by HPLC-DAD and results are expressed as $\mu \mathrm{g}$ per $\mathrm{g}$ of dry weight $(\mathrm{dw})$ in Table 2 . HPLC-DAD chromatograms of standards and $F$. torulosa were seen in Figs. 1-2. Totally 16 phenolic and organic acid compounds namely 
fumaric acid, gallic acid, protocatechuic acid, $p$ hydroxybenzoic acid, catechin hydrate, 6,7dihydroxy coumarin, 2,4 dihydroxybenzoic acid, caffeic acid, vanillin, $p$-coumaric acid, ferulic acid, coumarins, trans-2-hydroxycinnamic acid, ellagic acid, rosmarinic acid and transcinnamic acid were identified in the mushroom.

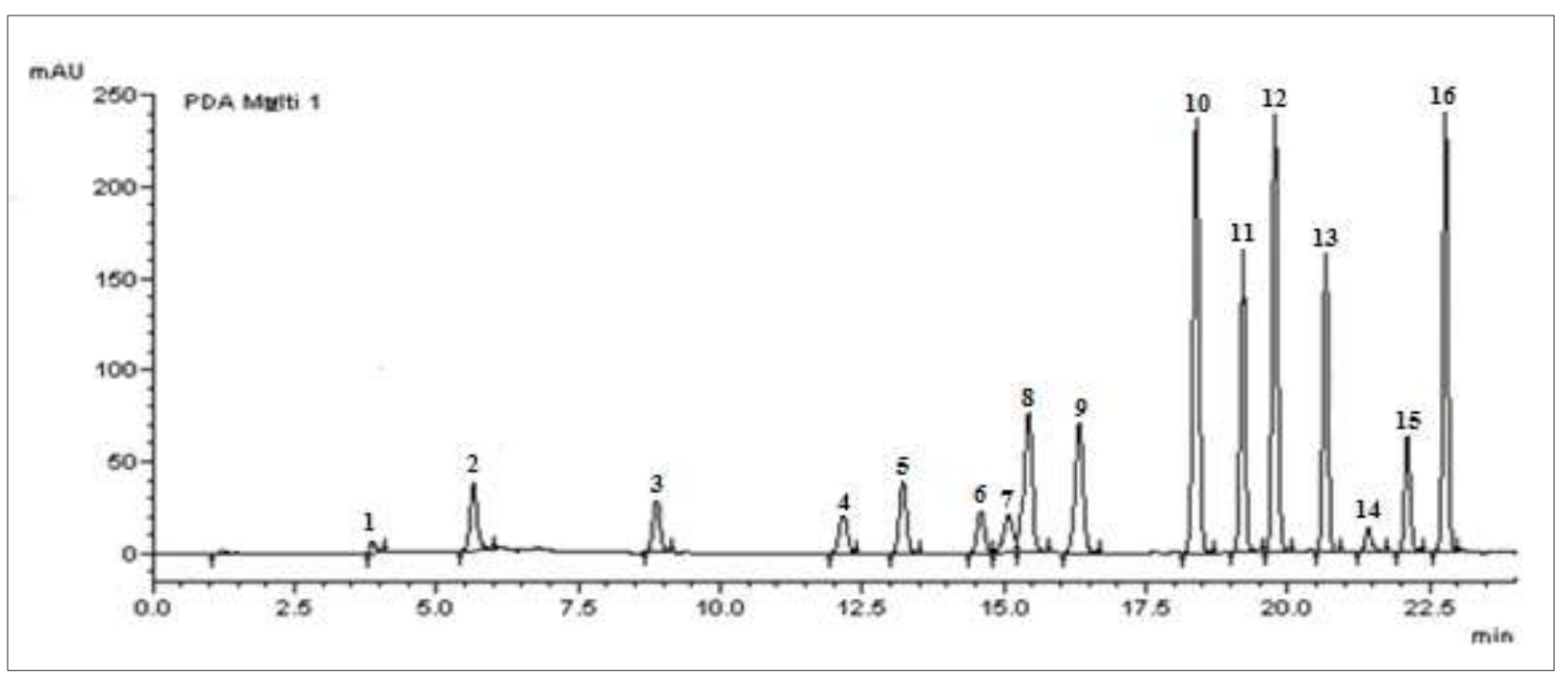

Fig. 1. The HPLC-DAD chromatogram of standards

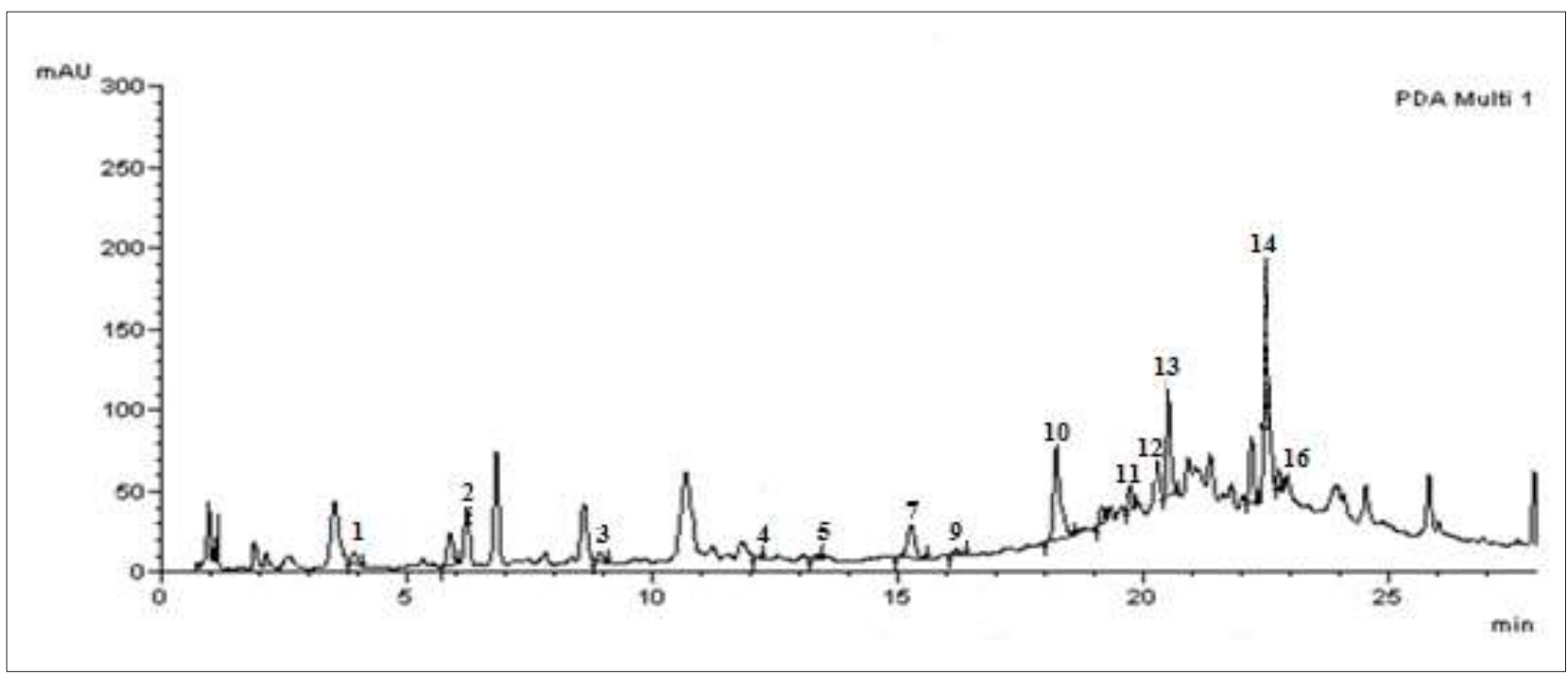

Fig. 2. The HPLC-DAD chromatogram of $F$. torulosa

As it seen Table 2, trans-2-hydroxy cinnamic acid $(10.05 \mu \mathrm{g} / \mathrm{g})$, gallic acid $(5.01 \mu \mathrm{g} / \mathrm{g})$ and $p$-coumaric acid $(3.04 \mu \mathrm{g} / \mathrm{g})$ were identified as major phenolic compounds in F. torulosa. Cinnamic acid derivatives are known to exhibit a range of bioactivities including antibacterial, antiviral, antifungal and antioxidant properties [24]. Gallic acid, mostly found in plants, have been reported to have antioxidant, antimicrobial, anti-inflammatory, and anticancer effects [25]. $p$-Coumaric acid is widespread in plants and mushrooms, in free or bound form. It is an important phenolic compound because of its antioxidant, anticancer, antimicrobial, antivirus, anti-inflammatory, antiplatelet aggregation, anxiolytic, antipyretic, analgesic, and anti-arthritis activities [26]. The high antioxidant activity exhibited by $F$. torulosa mushroom can be also influenced by the phenolic compounds it contains. Phenolic compounds of Inonotus obliquus (Fuscoporia obliqua) were analyzed using high performance liquid chromatography by Kim et 
al. [27] and $p$-hydroxybenzoic acid $(263 \mu \mathrm{g} / \mathrm{g})$, kaempferol $(53 \mu \mathrm{g} / \mathrm{g})$, quercetin $(52 \mu \mathrm{g} / \mathrm{g})$, homogentisic acid $(51 \mu \mathrm{g} / \mathrm{g})$ and protocatechuic acid $(50 \mu \mathrm{g} / \mathrm{g})$ were identified as major phenolic compounds. In the literature, there is only one study about phenolic compounds of $F$. torulosa. In the report of Bal et al. [28], benzoic acid (170.6), chlorogenic acid (42.7), gallic acid (9.8) and catechin (2.7) were identified in F. torulosa ethanol extract.

Table 2. Phenolic compounds of $F$. torulosa

\begin{tabular}{clcc}
\hline No & Compounds & Retention time $(\mathrm{min})$ & Composition $(\mu \mathrm{g} / \mathrm{g})$ \\
\hline 1 & Fumaric acid & 3.86 & 0.33 \\
2 & Gallic acid & 5.66 & 5.01 \\
3 & Protocatechuic acid & 8.88 & 0.17 \\
4 & p-Hydroxybenzoic acid & 12.18 & 0.01 \\
5 & Catechin hydrate & 13.22 & 0.91 \\
6 & 6,7-Dihydroxy coumarin & 14.60 & $\mathrm{nd}$ \\
7 & 2,4-Dihydroxybenzoic acid & 15.08 & 0.48 \\
8 & Caffeic acid & 15.42 & nd \\
9 & Vanillin & 16.33 & 0.07 \\
10 & p-Coumaric acid & 18.39 & 3.04 \\
11 & Ferulic acid & 19.21 & 0.46 \\
12 & Coumarin & 19.78 & 0.05 \\
13 & trans-2-Hydroxy cinnamic acid & 20.67 & 10.05 \\
14 & Ellagic acid & 21.41 & 0.39 \\
15 & Rosmarinic acid & 22.11 & $\mathrm{nd}$ \\
16 & trans-Cinnamic acid & 22.78 & 0.51 \\
\hline
\end{tabular}

nd: Not detected.

\subsection{Antioxidant Activity}

$\beta$-carotene-linoleic acid, DPPH free radical scavenging, ABTS cation radical scavenging, cupric-reducing antioxidant capacity (CUPRAC) and metal chelating activity assays were used to determine antioxidant activities of the hexane, chloroform, acetone, methanol and water extracts of $F$. torulosa. All of the extracts showed antioxidant activities in a dose-dependent manner. Table 3 shows the $\mathrm{IC}_{50}$ values and inhibition percentage (\%) at $200 \mu \mathrm{g} / \mathrm{mL}$ concentration of the extracts and standard compounds (BHA, $\alpha$-tocopherol, and EDTA).

The methanol extract of $F$. torulosa showed the highest antioxidant activity in all assays except metal chelating assay and followed by the acetone extract. Antioxidant activity of the methanol extract of $F$. torulosa was found to be higher than $\alpha$-tocopherol and BHA used as standards in $\mathrm{DPPH}^{\circ}, \mathrm{ABTS}^{\circ+}$ and CUPRAC assays with $\mathrm{IC}_{50}$ value of $15.03 \pm 0.25,10.06 \pm 0.87$ and $17.43 \pm 0.29 \mu \mathrm{g} / \mathrm{mL}$, respectively. When the acetone extract of $F$. torulosa showed higher antioxidant activity than $\alpha$-tocopherol in $\mathrm{DPPH}^{\circ}$ assay $\left(\mathrm{IC}_{50}: 25.66 \pm 0.38 \mu \mathrm{g} / \mathrm{mL}\right.$ ), it showed higher antioxidant activity than $\alpha$-tocopherol and BHA in $\mathrm{ABTS}^{\cdot+}\left(\mathrm{IC}_{50}: 11.53 \pm 0.41 \mu \mathrm{g} / \mathrm{mL}\right)$ and CUPRAC $\left(\mathrm{A}_{0.50}: 17.93 \pm 0.06 \mu \mathrm{g} / \mathrm{mL}\right)$ assays. The methanol extract with higher concentrations of phenolic contents showed the highest activity in all antioxidant activity assays except metal chelating assay. Szychowski et al. [22] investigated antiradical activity against $\mathrm{DPPH}^{\circ}, \mathrm{ABTS}^{\circ+}$ and inhibition of xanthine oxidase of $80 \%$ ethanol, $80 \%$ methanol, $95 \%$ ethanol and $95 \%$ methanol extracts of Inonotus obliquus (Fuscoporia obliqua). For $80 \%$ ethanol, $80 \%$ methanol, $95 \%$ ethanol and $95 \%$ methanol $\mathrm{IC}_{50}$ values were calculated as $279.60 \pm 81.17,447.70 \pm 16.18,412.30 \pm 52.12,404.10 \pm 84.14 \mu \mathrm{g} / \mathrm{mL}$ for DPPH ${ }^{*}$ assay; $4.17 \pm 0.76$, $4.60 \pm 2.52,4.83 \pm 1.07,4.73 \pm 0.13 \mu \mathrm{g} / \mathrm{mL}$ for $\mathrm{ABTS}^{*+}$ assay; $34.37 \pm 6.08,44.36 \pm 5.44$, $62.80 \pm 7.32,58.89 \pm 6.03 \mu \mathrm{g} / \mathrm{mL}$ for inhibition of xanthine oxidase assay. Previously, Khadhri et al. [29] studied antioxidant activity of the ethanol extract of $F$. torulosa by using DPPH' radical 
scavenging, the reducing power of iron and the iron-chelating power assays and the ethanol extract showed high antioxidant activity in $\mathrm{DPPH}^{*}$ and iron-chelating assays. In a different study, DPPH ${ }^{*}$ radical scavenging activities of the hexane, chloroform, $50 \%$ methanol and water extracts of $F$. torulosa were determined and the water extract indicated higher antioxidant activity among the other extracts [30]. Bal et al. [28] investigated $\mathrm{DPPH}^{*}$ radical scavenging activity of the ethanol extract of $F$. torulosa and the extract was found to have high activity. Antioxidant activity of crude extracts (water, $50 \% \mathrm{EtOH}, 80 \% \mathrm{EtOH}, \mathrm{EtOH}, \mathrm{EtOAc}$ ) of $F$. torulosa was tested by using $\mathrm{DPPH}^{*}$ assays and $\mathrm{IC}_{50}$ values were calculated as $134.27 \pm 1.41$, $18.88 \pm 0.38,7.30 \pm 0.34,19.23 \pm 0.42,49.57 \pm 0.96 \mu \mathrm{g} / \mathrm{mL}$, respectively [23]. Our results are in accordance with the literature. In this report, antioxidant activities of various extracts obtained from $F$. torulosa were investigated in details for the first time. 
Table 3. Antioxidant activity of the extracts of $F$. torulosa by $\beta$-Carotene-linoleic acid, DPPH ${ }^{*}$, ABTS $^{\circ+}$, CUPRAC and metal chelating assays ${ }^{\mathrm{a}}$

\begin{tabular}{|c|c|c|c|c|c|c|c|c|c|c|}
\hline & \multicolumn{10}{|c|}{ Antioxidant activity } \\
\hline & & \multicolumn{2}{|c|}{$\begin{array}{c}\beta \text {-Carotene-linoleic acid } \\
\text { assay }\end{array}$} & \multicolumn{2}{|c|}{ DPPH` assay } & \multicolumn{2}{|c|}{$\mathrm{ABTS}^{\cdot+}$ assay } & \multicolumn{2}{|c|}{ CUPRAC assay } & \multirow{2}{*}{$\begin{array}{c}\text { Metal } \\
\text { chelating assay }\end{array}$} \\
\hline & & $\begin{array}{l}\text { Inhibition (\%) } \\
\text { (at } 200 \mu \mathrm{g} / \mathrm{mL})\end{array}$ & $\begin{array}{c}\mathrm{IC}_{50} \\
(\mu \mathrm{g} / \mathrm{mL})\end{array}$ & $\begin{array}{l}\text { Inhibition (\%) } \\
\text { (at } 200 \mu \mathrm{g} / \mathrm{mL})\end{array}$ & $\begin{array}{c}\mathrm{IC}_{50} \\
(\mu \mathrm{g} / \mathrm{mL})\end{array}$ & $\begin{array}{l}\text { Inhibition (\%) } \\
\text { (at } 200 \mu \mathrm{g} / \mathrm{mL} \text { ) }\end{array}$ & $\begin{array}{c}\mathrm{IC}_{50} \\
(\mu \mathrm{g} / \mathrm{mL})\end{array}$ & $\begin{array}{c}\text { Absorbance } \\
\text { (at } 200 \mu \mathrm{g} / \mathrm{mL} \text { ) }\end{array}$ & $\begin{array}{c}\mathrm{A}_{0.50} \\
(\mu \mathrm{g} / \mathrm{mL})\end{array}$ & \\
\hline \multirow{5}{*}{ 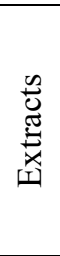 } & Hexane & $36.84 \pm 0.97$ & $>200$ & $4.39 \pm 0.48$ & $>200$ & $9.19 \pm 0.45$ & $>200$ & $0.44 \pm 0.01$ & $>200$ & $39.81 \pm 1.68$ \\
\hline & Chloroform & $82.09 \pm 0.76$ & $23.42 \pm 0.23$ & $5.70 \pm 0.39$ & $>200$ & $15.66 \pm 0.71$ & $>200$ & $0.45 \pm 0.01$ & $>200$ & $3.51 \pm 0.20$ \\
\hline & Acetone & $95.68 \pm 0.03$ & $3.59 \pm 0.27$ & $78.92 \pm 0.92$ & $25.66 \pm 0.38$ & $90.52 \pm 0.07$ & $11.53 \pm 0.41$ & $3.25 \pm 0.04$ & $17.93 \pm 0.06$ & $15.21 \pm 0.35$ \\
\hline & Methanol & $97.60 \pm 0.70$ & $2.57 \pm 0.01$ & $79.20 \pm 0.13$ & $15.03 \pm 0.25$ & $91.62 \pm 0.15$ & $10.06 \pm 0.87$ & $3.74 \pm 0.04$ & $17.43 \pm 0.29$ & $33.67 \pm 0.37$ \\
\hline & Water & $93.94 \pm 0.79$ & $8.23 \pm 0.31$ & $39.07 \pm 0.33$ & $>200$ & $37.58 \pm 0.71$ & $>200$ & $0.58 \pm 0.01$ & $151.41 \pm 0.12$ & $27.16 \pm 0.74$ \\
\hline \multirow{3}{*}{$\stackrel{\vec{D}}{\infty}$} & $\alpha$-Tocopherol & $90.51 \pm 0.18$ & $2.10 \pm 0.08$ & $87.14 \pm 0.28$ & $37.20 \pm 0.41$ & $85.83 \pm 0.12$ & $38.51 \pm 0.54$ & $0.85 \pm 0.02$ & $66.72 \pm 0.81$ & $\mathrm{NT}^{\mathrm{b}}$ \\
\hline & BHA & $92.80 \pm 0.02$ & $1.34 \pm 0.04$ & $88.36 \pm 0.29$ & $19.80 \pm 0.36$ & $86.70 \pm 0.10$ & $11.82 \pm 0.09$ & $2.47 \pm 0.01$ & $24.40 \pm 0.69$ & $\mathrm{NT}^{\mathrm{b}}$ \\
\hline & EDTA & $\mathrm{NT}^{\mathrm{b}}$ & $\mathrm{NT}^{\mathrm{b}}$ & $\mathrm{NT}^{\mathrm{b}}$ & $\mathrm{NT}^{\mathrm{b}}$ & $\mathrm{NT}^{\mathrm{b}}$ & $\mathrm{NT}^{\mathrm{b}}$ & $\mathrm{NT}^{\mathrm{b}}$ & $\mathrm{NT}^{\mathrm{b}}$ & $94.70 \pm 0.60$ \\
\hline
\end{tabular}

${ }^{a}$ Values represent the means \pm SEM of three parallel sample measurements $(p<0.05)$

${ }^{\mathrm{b}}$ NT: not tested. 


\subsection{Anticholinesterase Activity}

Acetylcholinesterase $(\mathrm{AChE})$ and butyrylcholinesterase $(\mathrm{BChE})$ inhibitory activities of the hexane, chloroform, acetone, methanol and water extracts of $F$. torulosa were screened by using Ellman method. All of the extracts showed anticholinesterase activities in a dosedependent manner. Inhibition percentage (\%) at $100 \mu \mathrm{g} / \mathrm{mL}$ concentration of the extracts and standard compound (galantamine) are given in Table 4.

Among the extracts, the hexane extract $(41.34 \pm 1.50 \%)$ of $F$. torulosa was found as the most active against AChE enzyme. The chloroform, acetone and methanol extracts indicated moderate activity against BChE enzyme with inhibition value of $35.18 \pm 0.55,40.78 \pm 0.30$ and $45.39 \pm 0.65 \%$, respectively, when the hexane and water extracts were found to be inactive. According to our knowledge, there is no study about anticholinesterase activities of Fuscoporia species in the literature.

Table 4. Cholinesterase inhibitory activities of the extracts of $F$. torulos $a^{\text {a }}$

\begin{tabular}{|c|c|c|c|}
\hline & & \multicolumn{2}{|c|}{ Cholinesterase Inhibitory Activity } \\
\hline & & AChE assay & BChE assay \\
\hline \multirow{5}{*}{ Extracts } & Hexane & $41.34 \pm 1.50$ & $\mathrm{NA}^{\mathrm{b}}$ \\
\hline & Chloroform & $8.42 \pm 0.28$ & $35.18 \pm 0.55$ \\
\hline & Acetone & $22.50 \pm 0.28$ & $40.78 \pm 0.30$ \\
\hline & Methanol & $14.80 \pm 0.06$ & $45.39 \pm 0.65$ \\
\hline & Water & $\mathrm{NA}^{\mathrm{b}}$ & $\mathrm{NA}^{\mathrm{b}}$ \\
\hline Standard & Galantamine & $78.76 \pm 0.52$ & $79.27 \pm 0.56$ \\
\hline
\end{tabular}

\section{CONCLUSION}

In this research, antioxidant and anticholinesterase activities of various extracts of $F$. torulosa were determined with the total phenolic contents. Also, phenolic profile of the mushroom analyzed by HPLC-DAD. The acetone and methanol extracts with the highest content of total phenolic contents displayed higher antioxidant activity than standards in DPPH', $\mathrm{ABTS}^{\cdot+}$ and CUPRAC assays. Totally, thirteen phenolic compounds were identified by using HPLC-DAD and trans-2-hydroxy cinnamic acid, gallic acid, $p$-coumaric acid were found as major phenolic compounds. In conclusion, this study reveals that extracts obtained from $F$. torulosa mushroom could be used as promising antioxidant and anticholinesterase agents. However, it is necessary to carry out isolation studies to discover the compounds responsible for these bioactivities.

\section{Conflict of Interest}

The authors declare that there is no conflict of interests in this current study.

\section{Acknowledgement}

This study is a part of E.D.'s Ph.D. thesis. The authors would like to thank the Scientific and Technological Research Council of Turkey for financial support under project TUBITAK114Z550. The Mugla Sitki Kocman University Research Fund is also acknowledged under project number (MUBAP 15/238).

\section{Orcid}

Mehmet Emin Duru (iD http://orcid.org/0000-0001-7252-4880 


\section{REFERENCES}

[1] Kumar, A. (2009) Antioxidant effect of Adiantum capillus veneris Linn on human lymphocyte: An in vitro study. J. Cell Tissue Res., 9, 1899-1902.

[2] Cakmak, Y.S., Zengin, G., Eskin, B., Yıldırım, K., Topal, M., Aydın, G.H., Unlu, E., Baydemir, M., \& Erten, K. (2017). Medicago rigidula (L.) ALL.'nın antioksidan ve enzim inhibisyon aktiviteleri ve fenolik bileșiminin incelenmesi. Marmara Pharm. J., 21/3, 522529.

[3] Loganayaki, N., Siddhuraju, P., \& Manian, S. (2013). Antioxidant activity and free radical scavenging capacity of phenolic extracts from Helicteres isora L. and Ceiba pentandra L. Food Sci. Technol., 50(4), 687-695.

[4] Özkay, Y., Yurttaş, L., Mohsen, U.A., Sever, B., Hussein, W., Öztürk, Ö., Sağlık, B.N., Acar, U., Erdoğan, Ö.N., Pekbağ, A., \& Kaplancıkl1, Z.A. (2014). Study on thiazolylhydrazone derivatives as acetylcholinesterase inhibitors. Marmara Üniversitesi Sağllk Bilimleri Enstitüsü Dergisi, 4(1), 38-42.

[5] Giacobini, E. (2004). Cholinesterase inhibitors: New roles and therapeutic alternatives. Pharmacol. Res., 5, 433-440.

[6] Asadipour, A., Alipour, M., Jafari, M., Khoobi, M., Emami, S., Nadri, H., Sakhteman, A., Moradi, A., Sheibani, V., Moghadam, F.H., Shafiee, A., \& Foroumadi, A. (2013). Novel coumarin-3-carboxamides bearing N-benzylpiperidine moiety as potent acetylcholinesterase. Eur. J. Med. Chem., 70, 623-630.

[7] Vina, J., Lloret, A., Giraldo, E., Badia, M.C., \& Alonso, M.D. (2011). Antioxidant pathways in Alzheimer's disease: Possibilities of intervention. Curr. Pharm. Des., 17(35), 38613864.

[8] Gutzmann, H., \& Hadler, D. (1998). Sustained efficacy and safety of idebenone in the treatment of Alzheimer's disease: Update on a 2-year double-blind multicenter study. $J$. Neural. Transm. Suppl., 54, 301-310.

[9] Zhang, M., Cui, S.W., Chueng, P.C., \& Wang, K.Q. (2006). Polysaccharides from mushrooms: A review on their isolation process, structural characteristics and antitumor activity. Trends Food Sci. Tech., 18, 4-19.

[10] Rout, S., \& Banerjee, R. (2007). Free radical scavenging, anti-glycation and tyrosinase inhibition properties of a polysaccharide fraction isolated from the rind from Punica granatum. Bioresource Technol., 98, 3159-3163.

[11] Moradali, M.F., Mostafavi, H., Ghods, S., \& Hedjaroude, G.A. (2007). Immunomodulating and anticancer agents in the realm of macromycetes fungi (Macrofungi). Int.l Immunopharmacol., 7, 701-724.

[12] Huang, Q.L., Jin, Y., Zhang, L.N., Cheung, C.K., \& Kennedy, J.F. (2007). Structure, molecular size and antitumor activities of polysaccharides from Poria cocos mycelia produced in fermenter. Carbohyd. Polym., 70, 324-333.

[13] Gern, R.M.M., Wisbeck, E., Rampinelli, J.R., Ninow, J.L., \& Furlan, S.A. (2008). Alternative medium for production of Pleurotus ostreatus biomass and potential antitumor polysaccharides. Bioresource Technol., 99, 76-82.

[14] Tong, H., Xia, N., Feng, K., Sun, G., Gao, X., Sun, L., Jiang, R., Tian, D., \& Sun, X. (2009). Structural characterization and in vitro antitumor activity of a novel polysaccharide isolated from the fruiting bodies of Pleurotus ostreatus. Bioresource Technol., 100, 16821686.

[15] Öztürk, M., Tel-Cayan, G., Muhammad, A., Terzioglu, P., \& Duru, M.E. (2015). Mushrooms: a source of exciting bioactive compounds, Atta-ur-Rahman (editör), Studies in Natural Product Chemistry, vol. 45. Elsevier, Amsterdam, Netherlands, pp. 363-456. 
[16] Lindequist, U., Niedermeyer, T.H.J., \& Julich, W. (2005). The pharmacological potential of mushrooms. Evid-Based Compl. Alt. 2(3), 285-299.

[17] Slinkard K., \& Singleton V.L. (1977). Total phenol analyses: Automation and comparison with manual methods. Am. J. Enol. Viticult., 28, 49-55.

[18] Tel-Çayan, G., Öztürk, M., Duru, M. E., Rehman, M., Adhikari, A., Türkoglu, A., \& Choudhary, M. I. (2015). Phytochemical investigation, antioxidant and anticholinesterase activities of Ganoderma adspersum. Ind. Crops Prod., 76, 749-754.

[19] Tel, G., Apaydın, M., Duru, M.E., \& Öztürk, M. (2012). Antioxidant and cholinesterase unhibition activities of three Tricholoma species with total phenolic and flavonoid contents: The edible mushrooms from Anatolia. Food Anal. Method., 5, 495-504.

[20] Ellman, G.L., Courtney, K.D., Andres, V., \& Featherston, R.M. (1961). A new and rapid colorimetric determination of acetylcholinesterase activity. Biochem. Pharmacol., 7, 8895.

[21] Zhang, N., Chen, H., Zhang, Y., Xing, L., Li, S., Wang, X., \& Sun, Z. (2015). Chemical composition and antioxidant properties of five edible Hymenomycetes mushrooms. Int. J. Food Sci. Tech., 50, 465-471.

[22] Szychowski, K.A., Rybczyńska-Tkaczyk, K., Tobiasz, J., Yelnytska-Stawasz, V., Pomianek, T., \& Gmiński, J. (2018). Biological and anticancer properties of Inonotus obliquus extracts. Process Biochem., 73, 180-187.

[23] Seephonkai, P., Samchai, S., Thongsom, A., Sunaart, S., Kiemsanmuang, B., \& Chakuton, B. (2011). DPPH radical scavenging activity and total phenolics of Phellinus mushroom extracts collected from northeast of Thailand. Chin. J. Nat. Medicines, 9(6), 0441-0445.

[24] Sova, M. (2012). Antioxidant and antimicrobial activities of cinnamic acid derivatives. Mini-Rev. Med. Chem., 12, 749-767.

[25] Fernandes, F.H.A, \& Salgado, H.R.N. (2016). Gallic Acid: Review of the methods of determination and quantification. Crit. Rev. Anal. Chem., 46(3), 257-265.

[26] Pei, K., Ou, J., Huanga, J., \& Oua, S. (2016). p-Coumaric acid and its conjugates: dietary sources, pharmacokinetic properties and biological activities. J. Sci. Food Agr., 96, 29522962.

[27] Kim, M.Y., Seguin, P., Ahn, J.K., Kim, J.J., Chun, S.C., Kim, E.H., Seo, S.H., Kang, E.Y., Kim, S.L., Park, Y.J, Ro, H.M., \& Chung, I.M. (2008). Phenolic compound concentration and antioxidant activities of edible and medicinal mushrooms from Korea. J. Agric. Food Chem., 56, 7265-7270.

[28] Bal, C., Akgul, H., Sevindik, M., Akata, I., \& Yumrutas, O. (2017). Determination of the anti-oxidative activities of six mushrooms. Fresen. Environ. Bull., 26, 6246-6252.

[29] Khadhri, A., Aouadhi, C., \& Aschi-Smiti, S. (2011). Screening of bioactive compounds of medicinal mushrooms collected on Tunisian Territory. Int. J. Med. Mushrooms, 19(2), 127-135.

[30] Kovacs, B., Zomborszki, Z.P., Orban-Gyapai, O., Csupor-Loffler, B., Liktor-Busa, E., Lazar, A., Papp, V., Urban, E., Hohmann, J., \& Vanyolos, A. (2017). Investigation of antimicrobial, antioxidant, and xanthine oxidase--1nhibitory activities of Phellinus (Agaricomycetes) mushroom species native to Central Europe. Int. J. Med. Mushrooms, 19(5), 387-394. 